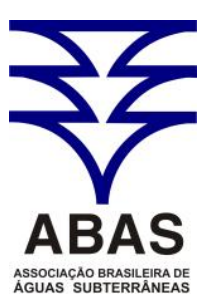

ASSOCIACAO BRASILERADE
AGUAS SUBTERRANEAS www.abas.org

\title{
AVALIAÇÃO DO PROCESSO DE INFILTRAÇÃO DA ÁGUA EM UM SOLO RESIDUAL COM DIFERENTES DECLIVIDADES EM LISÍMETROS DE LABORATÓRIO
}

\author{
EVALUATION OF WATER INFILTRATION PROCESS IN RESIDUAL SOIL \\ WITH DIFFERENT SLOPE IN LABORATORIAL LYSIMETERS
}

\author{
Nilton Santos Paes Junior ${ }^{1}$, George de Paula Bernardes²
}

Artigo recebido em: 24/01/2013 e aceito para publicação em: 19/05/2013

\begin{abstract}
This research paper evaluates the process of water infiltration in a residual soil of biotite-gneiss very weathered from the region of Paraíba Valley, SP, considering different slope inclinations, making use of a physical model. The model developed in the laboratory, consists of a lysimeter glass box with a simulated rainfall with spreaders. The residual soil was air dried and trimmed before insertion inside the lysimeter by layers of $3 \mathrm{~cm}$, being compacted with a specified energy in order to reproduce the unit dry specific weight and void ratio close to the field values. During the test, each the parcels of water were evaluated by volumetric measurement and temporal relations. The wetting front development was registered with a digital camera. A complete soil characterization was carried out and soil characteristic curve were performed for test interpretation and modeling input. With the numerical model of Green-Ampt applied to the results it was possible to observe the influence of the slope inclination on the position of the wet front in relation to the transition zone. Increasing the slope inclination, the velocity of the wet front reduces which increase the transmission zone with a smooth front. This difference can reach about $36 \%$ between $5 \%$ and $50 \%$ slope inclination.
\end{abstract}

Keywords: Infiltration. Surface Slope. Lysimeter.

Resumo: Este trabalho de pesquisa tem por objetivo avaliar o processo de infiltração da água em um solo residual de biotita-gnaisse muito intemperizado da região do Vale do Paraíba, SP, considerando a superfície do terreno com diferentes declividades, utilizando um lisímetro de laboratório. Ao lisímetro de laboratório construído em vidro, foram acoplados um simulador de chuva e um regulador de declividade. O solo foi inicialmente seco ao ar, destorroado e então depositado no interior do lisímetro em camadas de $3 \mathrm{~cm}$, compactado de forma padronizada para atingir um índice de vazios semelhante ao campo. No decorrer dos ensaios, as parcelas do balanço hídrico foram avaliadas por meio de relações temporais e volumétricas. $\mathrm{O}$ avanço da frente de umedecimento foi monitorado por meio de câmera filmadora. Ensaios de caracterização geotécnica e determinação da curva característica foram executados para a obtenção dos parâmetros necessários à interpretação e modelagem teórica dos resultados. O modelo teórico de Green-Ampt permitiu representar a frente de umedecimento e a zona de transmissão, nas quais foi possível observar a influência da declividade. $\mathrm{O}$ aumento da declividade provocou uma redução da velocidade do avanço da zona de transmissão em relação à frente de umedecimento. Essa diferença chegou, em média, a 36\% entre a superfície com $5 \%$ e $50 \%$ de declividade.

Palavras-chave: Infiltração, Declividade da superfície, Lisímetro.

\section{INTRODUÇÃO}

O crescimento acelerado e desordenado no Vale do Rio Paraíba do Sul vem comprometendo de forma alarmante os recursos hídricos da região os quais apresentam sérios sinais de deterioração. Dentro desse cenário os Comitês de Bacias Federais (CEIVAP) e Estadual (CBH-PS) vêm buscando soluções para mitigar às ações antrópicas de modo a garantir um crescimento sustentável.
Os principais problemas na região, ao qual apresenta um relevo bem acidentado, são as extensas áreas de pastos abandonados e degradados, com muito solo exposto e compactado o que reduz consideravelmente a infiltração e aumenta o escoamento superficial.

Sabe-se que a melhoria das condições de infiltração da água no solo é fundamental para a

1 Departamento de Águas e Energia Elétrica do Estado de São Paulo (niltonjr.paes@gmail.com).

2 Faculdade de Engenharia de Guaratinguetá - Universidade Estadual Paulista (UNESP) (gpb@ feg.unesp.br). 
manutenção da dinâmica das águas subterrâneas e da recarga dos aquíferos, por outro lado, reduz o escoamento superficial minimizando as enchentes. Estudos sobre a infiltração da água no solo são relativamente recentes, datando desde fins do século XIX e início do século XX (CECÍLIO, 2002).

Autores como Bertoni e Lombardi Neto (1999) ressaltam também a importância do conhecimento da infiltração da água na determinação das perdas de solo decorrentes de processos erosivos, com consequência negativa direta na produção agrícola e comprometimento das redes de drenagens e dos rios devido ao assoreamento.

$\mathrm{O}$ entendimento do processo de infiltração e de suas relações com as propriedades físicas dos solos é fundamental para a solução de problemas relativos às áreas de irrigação, drenagem, conservação do solo e da água e controle do escoamento superficial (PRUSKI et al., 1997).

As propriedades físicas do solo, em especial, a textura e estrutura granular, podem afetar significativamente a sua Capacidade de Campo. Além disso, o conteúdo de água no solo é função do tamanho e do volume dos seus poros, estando a umidade diretamente relacionada à pressão capilar (TUCCI, 1993).

Autores como Ahrendt (2005) e Camarinha (2011) afirmam que a declividade dos terrenos não influencia na velocidade de infiltração propriamente dita, mas sim na quantidade de água disponível na superfície do terreno para ser infiltrada. Além disso, segundo Miyazaki (2006), a declividade influencia na profundidade alcançada pela frente de saturação e no tempo necessário para que esta saturação ocorra.

$\mathrm{O}$ entendimento do processo de infiltração e suas correlações com os volumes retido e escoado subsuperficialmente podem ser avaliados e quantificados através de lisímetros. Os diferentes tipos de lisímetros, monitoramento das variáveis e forma de utilização foram apresentados por Allen et al. (1991).

Observa-se na literatura a existência de vários experimentos utilizando lisímetros para o estudo das variáveis hidrológicas (FELTRINI, 2009), influência do sistema de manejo (OLIVEIRA, 2006; BARCELOS et al., 1999), perda de água por evapotranspiração (PERUCHI, 2009; MEDEIROS, 2002) e o efeito da chuva sobre taludes (VALLEJO, 1982; TAMI et al., 2004; SOARES, 2006), em que os autores concluíram que a modelagem mostrou ser uma ferramenta bastante útil para o entendimento do processo de movimento da água no solo.

Este trabalho avalia o processo de infil- tração, retenção e percolação da água de chuva através de um solo residual de alteração de rocha biotita-gnasse (horizonte B) utilizando um lisímetro de laboratório.

\section{MATERIAIS E MÉTODOS}

Para este estudo, foram construídos: um lisímetro equipado com regulador de declividade e um simulador de chuva regulável. Durante os ensaios foram monitorados os escoamentos, superficial e subsuperficial e a evolução da frente de umedecimento. O modelo de Green \& Ampt, foi utilizado para representar a evolução da frente de umedecimento, caracterizada por ser o limite visível do movimento da água no solo, e a zona de transmissão, determinada pela diferença entre os volumes precipitado e escoado superficialmente.

\section{A construção do lisímetro}

O lisímetro construído, mede internamente $90 \mathrm{~cm}$ de comprimento, $15 \mathrm{~cm}$ de largura e 28 $\mathrm{cm}$ de altura, utiliza placas de vidro com $5 \mathrm{~mm}$ de espessura devidamente vedadas com borracha de silicone (Figura 1).

O lisímetro foi instalado sobre uma prancha de madeira e fixado nas extremidades por calços para a sustentação e inclinação do dispositivo com declividades de 5, 15, 30 e 50\%.

\section{Instrumentação}

Para a captação e medição do escoamento subsuperficial foi construída uma camada drenante no fundo composta por pedrisco de diâmetro variando entre 1,70 e 2,00mm e manta de geotêxtil não-tecido (previamente saturada) para evitar perda de material. O geotêxtil utilizado apresenta uma espessura de $2,0 \mathrm{~mm}$, abertura de poros aparente $\left(\mathrm{O}_{95}\right)$ variando de 0,13 a $0,23 \mathrm{~mm}$ e coeficiente de permeabilidade normal de $3,5 \times 10^{-1} \mathrm{~cm} / \mathrm{s}$. A mesma manta de geotêxtil foi posicionada na superfície do solo para evitar o impacto direto das gotas e risco de erosão. O geotêxil garante também, uma carga hidráulica constante de 2,0 $\mathrm{mm}$ sobre a superfície do solo.

A coleta do escoamento superficial foi realizada através de uma calha plástica fixada na face rebaixada do lisímetro. Uma mangueira fixada no fundo da calha conduzia à água para a bureta de medição.

A evolução da frente de umedecimento foi obtida em função da leitura de uma fita métrica fixada à parede do lisímetro, onde em intervalos de tempo pré-estabelecidos uma câmera filmadora digital comum registrava a posição da frente. 


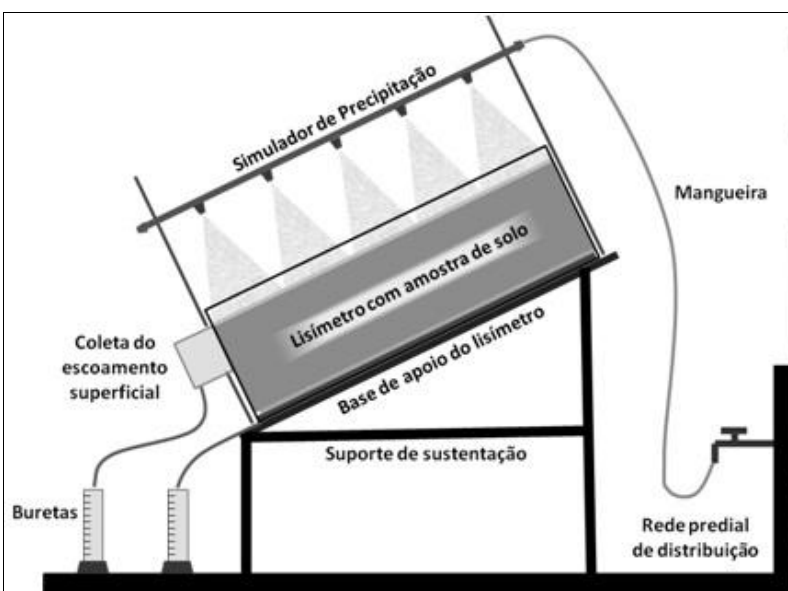

(a)

Figura 1 - Esquema (a) e foto do experimento (b)

Figure 1 - Scheme (a) and photo of the experiment (b)

\section{Construção do simulador de chuva}

O sistema de simulação de precipitação desenvolvido neste trabalho é bastante simples quando comparados com trabalhos anteriores, uma vez que não avalia características como o volume e densidade espacial das gotas e nem a velocidade de impacto das mesmas, além ainda de ser abastecido diretamente pela rede de distribuição de água predial do laboratório, sem a utilização de bomba d'água.

De baixo custo, fácil ajuste e operação, o sistema utiliza 5 pulverizadores modelo Ultrajet da marca Guarany ${ }^{\circledR}$ alinhados em um tubo de PVC de 20,0 mm (Figura 1). Com um espaçamento de $15,0 \mathrm{~cm}$ entre pulverizadores e altura de $30,0 \mathrm{~cm}$, o simulador foi capaz de aplicar água em toda a superfície do solo a uma intensidade de $148 \mathrm{~mm} / \mathrm{h}$. O controle da pressão da rede de distribuição predial foi feito através de um manômetro com escala até 2 atm, instalado antes do simulador.

Como a pressão da rede apresentou pequenas alterações ao longo de uma semana de observação, antes de cada ensaio o simulador era ajustado de forma a garantir a aplicação de uma mesma intensidade de precipitação em todos os ensaios.

O procedimento de ajuste do simulador foi dividido em duas etapas: a aferição individual dos bicos e a aferição do sistema. Para a aferição individual dos bicos utilizou-se uma bureta graduada de $100 \mathrm{ml}$ e um cronômetro, sendo os bicos considerados calibrados quando apresentassem a mesma vazão. Para aferição do sistema foram utilizadas duas técnicas, o uso de pluviômetros instalados no interior do lisímetro e a

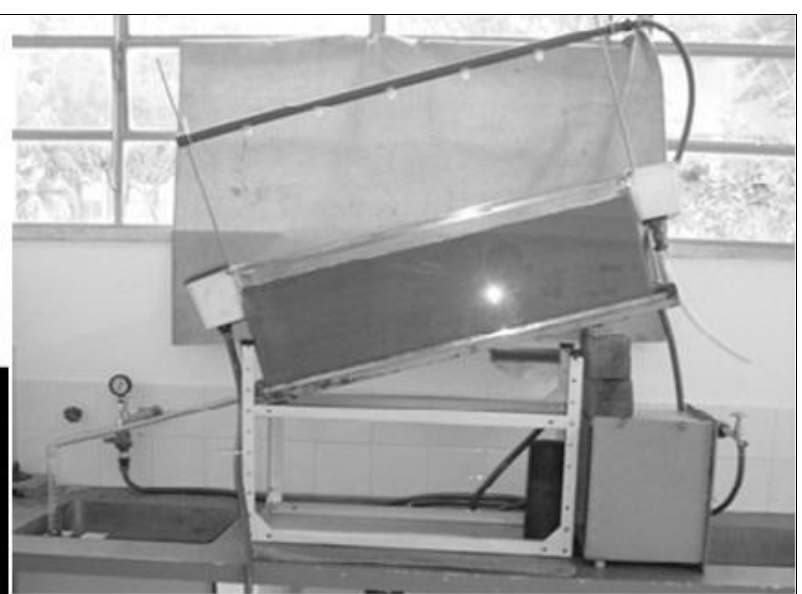

(b)

medida do volume escoado pelo fundo da caixa durante um intervalo de tempo de precipitação pré-estabelecido.

\section{Preparo e disposição do solo}

O solo utilizado nos ensaios foi retirado de uma jazida localizada na base da serra Quebra Cangalha, município de Lorena-SP (Figura 2).

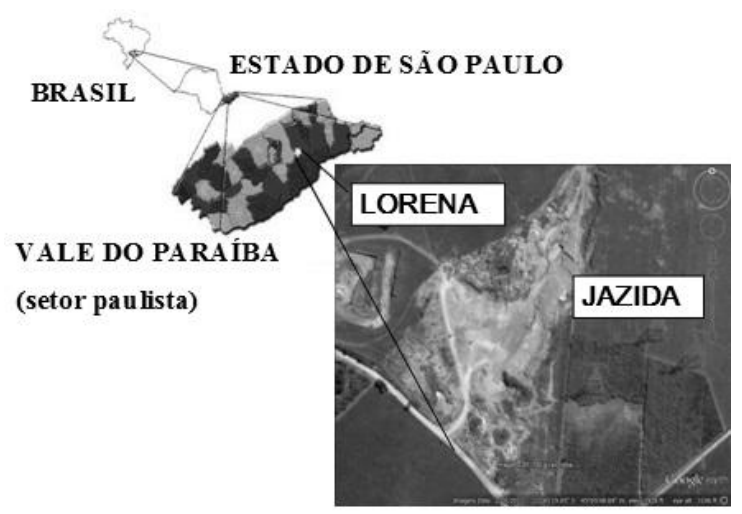

Figura 2 - Localização da Jazida $\left(22^{\circ} 45^{\prime} 19,05^{\prime \prime} \mathrm{S}\right.$ e $45^{\circ} 05^{\prime} 08,69^{\prime}$ ' W).

Figure 2 - Location of the excavation $\left(22^{\circ} 45^{\prime} 19,05^{\prime \prime}\right.$ S e $45^{\circ} 05^{\prime} 08,69^{\prime \prime} \mathrm{W}$ ).

Essa jazida é utilizada pela secretaria de obras do município para manutenção das estradas rurais e construção de novas estradas.

O material consiste em um solo residual maduro de biotita-gnaisse resultado do processo de intemperismo de rocha gnaisse do PréCambiano.

Inicialmente foi realizada a caracterização física do solo com base em sete amostras 
moldadas no campo, utilizando anéis metálicos com 7,0 cm de diâmetro e $3,0 \mathrm{~cm}$ de altura e coleta de amostras amolgadas para ensaios de caracterização em laboratório. Os resultados indicaram que no campo existe uma variação do peso específico seco entre $12,0 \mathrm{kN} \cdot \mathrm{m}^{-3}$ e 17,0 $\mathrm{kN} \cdot \mathrm{m}^{-3} \mathrm{e}$ índice de vazios entre 0,624 e 1,235.

Uma simples análise da porcentagem de finos do material com base no peneiramento na \#200 (diâmetro menores que $0,074 \mathrm{~mm}$ ) constatou uma variação de $15 \%$ de finos. Assim, considerando a dificuldade de moldagem dos blocos com as dimensões do lisímetro, a não garantia do contato uniforme entre o solo e o vidro, como também, a variabilidade inerente das propriedades do solo no campo, optou-se por realizar o estudo através de amostras remoldadas. As amostras foram remoldadas por compactação leve, procurando representar a faixa de valores do peso específico de campo e de seus respectivos índices de vazios.

O solo foi disposto em bandejas para secagem ao ar livre, separação de raízes e pedregulhos segundo os critérios da NBR- 6457/1986 (Preparo de amostras de solo para ensaio normal de compactação e ensaios de caracterização). Após a determinação da umidade higroscópica, o solo foi destorroado utilizando um tarugo de madeira mole tipo balsa pressionado sobre pequenas porções de solo até que se atingisse uma textura a qual não se observava grumos. O procedimento de colocação do solo no lisímetro foi definido através de testes realizados com vários anéis de 3,0 cm de altura e 5,0 cm de diâmetro. Para a quantidade de solo calculado com base no peso específico e índice de vazios médios de campo, o número de golpes e a altura de queda foram definidos para um soquete de $140 \mathrm{~g}$. A amostra remoldada com as características semelhantes à de campo foi obtida para uma compactação com cinco golpes e altura de queda de 1,0 $\mathrm{cm}$. A Figura 3-a ilustra a compactação teste e a Figura 3-b o procedimento de compactação dentro do lisímetro.

Os ensaios foram realizados com o reaproveitamento do solo, em que após cada ciclo, o material foi retirado do lisímetro e disposto em bandejas galvanizadas para a secagem em estufa. Após cada destorroamento e homogeneização, o solo era deixado exposto ao ar por 48 horas para recuperação da umidade higroscópica. Uma pequena quantidade de solo era peneirada para verificação da quantidade de finos. Para garantir a qualidade das montagens e representatividade do experimento com relação ao campo, o mesmo peso total de solo era utilizado para preenchimento do lisímetro, onde o processo de lançamento em camadas de $3,0 \mathrm{~cm}$ e compactação seguiram o mesmo procedimento em todos os testes.

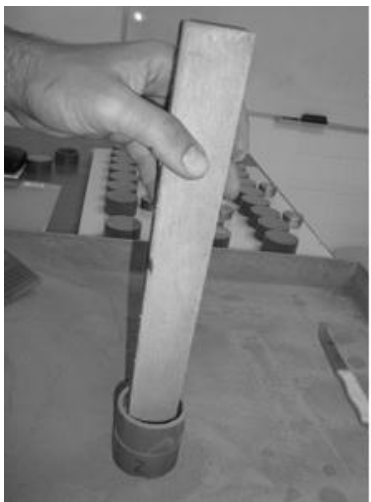

(a)

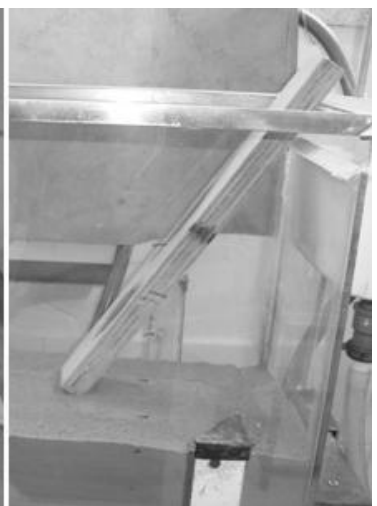

(b)
Figura 3 - Compactação teste (a) e compactação no lisímetro (b)

Figure 3 - Compaction test (a) and compaction inside the lysimeter (b)

\section{Parâmetros geotécnicos do solo}

Os ensaios de caracterização foram realizados seguindo os procedimentos preconizados pela Associação Brasileira de Normas Técnicas: NBR 6457/1986 - Amostras de solos - Preparação para ensaios de compactação e caraterização; NBR 6459/1984 - Determinação do limite de liquidez; NBR 7180/1984 - Determinação do limite de plasticidade; NBR 6508/1984 - Massa específica real dos grãos; NBR 7181/1984 Análise granulométrica.

As principais equações de apoio utilizadas na determinação dos índices físico complementares do solo estão apresentadas na Tabela 1.

O solo foi caracterizado também em função da sequencia de destorroamento de modo a avaliar o efeito do reuso nos seus parâmetros.

As propriedades hidráulicas e de retenção do solo foram obtidas dos ensaios de permeabilidade realizados por Almeida (2012) e a curva de retenção da água no solo (CRUS) foi determinada pelo método do papel filtro (Marinho,1994; ASTM: D 5298-94).

A curva de retenção da água no solo foi ajustada pelo modelo de Duplo Van Genuchten (CARDUCCI et al., 2011) segundo a equação 1:

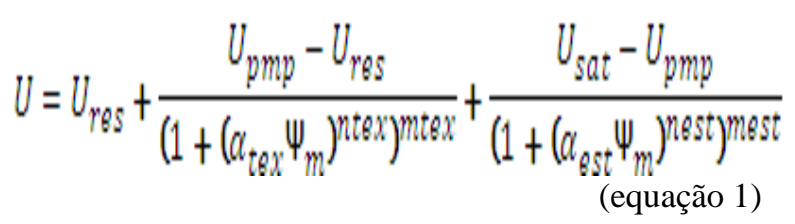


Tabela 1 - Índices físicos do solo

Table 1 - Soil phase relationships

\begin{tabular}{|c|c|}
\hline$\rho_{n}=\frac{m}{v}$ & $\omega_{n}=\frac{m a}{m s}$ \\
\hline$\gamma=\rho \times g$ & $\gamma_{d}=\frac{\gamma_{n a t}}{1+w}$ \\
\hline$\gamma_{s}=G s \times \gamma_{w}$ & $e=\frac{\gamma_{s}}{\gamma_{d}}-1$ \\
\hline$\eta=\frac{e}{1+e}$ &
\end{tabular}

Onde: $\rho_{\mathrm{n}}$ : massa específica natural; $m$ : massa de solo; $v$ : volume de solo; $\gamma$ : peso específico; $g$ : aceleração da gravidade $\gamma_{s}$ : peso específico dos sólidos; $G_{S}$ : densidade dos grãos; $\gamma_{w}$ : peso específico da água; $\eta$ : porosidade; $e$ : índice de vazios; $w_{n}$ : umidade natural; ma: massa de água; $m s$ : massa de solo; $\gamma_{d}$ : peso específico seco; $\gamma_{n a t}$ : peso específico natural; $w$ : umidade.

Com restrição de $m=1-1 / n$ (Mualem, 1976), considerados para ambos os seguimentos da curva, estrutural $\left(m_{\text {est }}\right)$ e textural $\left(m_{\text {tex }}\right)$. A umidade gravimétrica e o potencial matricial são representados por $\mathrm{U}(\%)$ e $\Psi_{\mathrm{m}}(\mathrm{KPa})$, respectivamente (Figura 4).

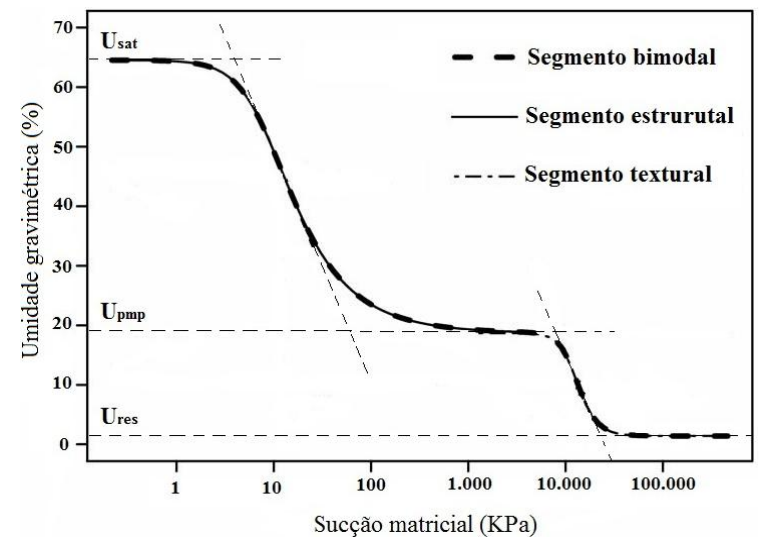

Figura 4 - Localização dos parâmetros associados à equação Duplo Van Genuchten

Figure 4 - Location of the parameters associated with the Double Van Genuchten equation

Os parâmetros $\mathrm{U}_{\text {res }}, \mathrm{U}_{\mathrm{pmp}}$, e $\mathrm{U}_{\text {sat }}$ representam o platô assintótico inferior $\left(\Psi_{\mathrm{m}} \rightarrow \infty\right)$ ou conteúdo de água residual assintótica; o platô intermediário, ou seja, valor do conteúdo de água que se observa ligeiramente constante ao redor do ponto de murcha permanente e o platô assintótico superior $\left(\Psi_{\mathrm{m}} \rightarrow 0\right)$, que indica o conteúdo de água na saturação, respectivamente. Os parâmetros $\alpha$ e $n$ estão associados à escala $\mathrm{e}$ forma da curva, entre as assíntotas superior, intermediária e inferior; $\alpha_{\text {est }}$ e $n_{\text {est }}$ (estrutural) correspondem ao primeiro segmento e $\alpha_{\text {tex }}$ e $n_{\text {tex }}$ (textural) ao segundo segmento da curva.

A curva de distribuição de poros foi determinada pelo método da derivação da curva característica, obtendo-se um gráfico $d \theta / d \Psi_{m}$ versus $\Psi_{m}$ (Figura 5). A interpretação da curva apresentada abaixo é feita com base no efeito da aplicação de uma variação de sucção $\Delta \Psi_{m}=\Psi_{m 2}$ - $\Psi_{m 1}$ à qual drenará poros com raios entre $r_{2} \mathrm{e}$ $r_{1}$.

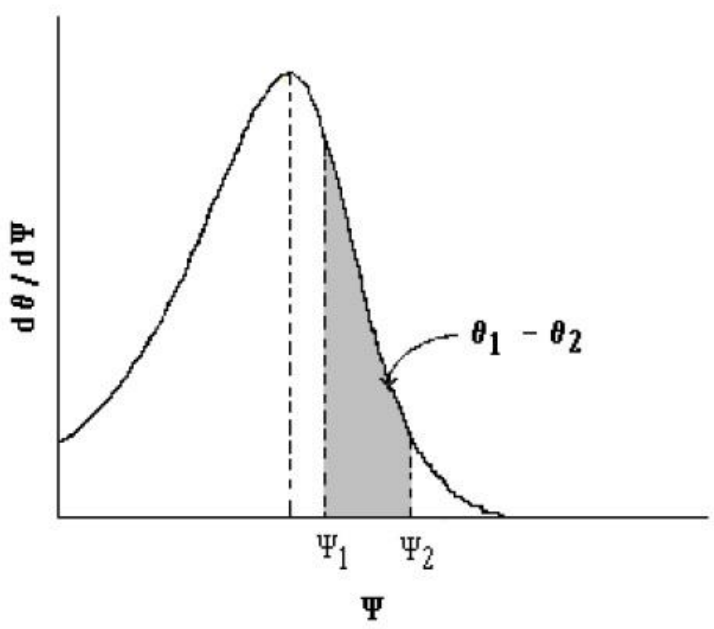

Figura 5 - Curva diferencial da CRUS (Santos, 2005) Figure 5 - Differential curve of CRUS (Santos, 2005)

Assim, o volume de água extraído do solo com a variação da tensão de $\Psi_{m 1}$ para $\Psi_{m 2}$, o qual é obtido pela diferença de umidades $\theta_{2}$ $\theta_{1}$, é igual ao volume de poros de raio compreendido entre $r_{l}$ e $r_{2}$ esvaziados na amostra.

A determinação do diâmetro equivalente drenado $\left(d_{p}\right)$ é obtida pela equação 2 abaixo:

$d p=2 . r=\frac{4 . \sigma}{\rho . g \cdot \Psi_{m}} \quad$ (equação 2)

Onde as variáveis da equação são a tensão superficial da água $\left(\sigma, \mathrm{Kg}_{\text {. }}{ }^{-2}\right)$, a densidade da água $\left(\rho, \mathrm{Kg} \cdot \mathrm{m}^{-3}\right)$, a aceleração da gravidade $\left(g, \mathrm{~m}^{*} \mathrm{~s}^{-2}\right)$ e potencial matricial $\left(\Psi_{m}, \mathrm{KPa}\right)$.

\section{Modelagem Teórica da Infiltração}

Segundo Vieira (2005), a infiltração depende do perfil de umidade volumétrica do solo, o qual é dividido, segundo Bond \& Collis-George (1981a) apud Oliveira (2003), em cinco zonas ou regiões de teores de umidade diferentes. A representação deste perfil pode ser visualizada na Figura 6. O entendimento destas diferentes zonas de umedecimento será de fundamental importância para a modelagem do processo de infiltração. 

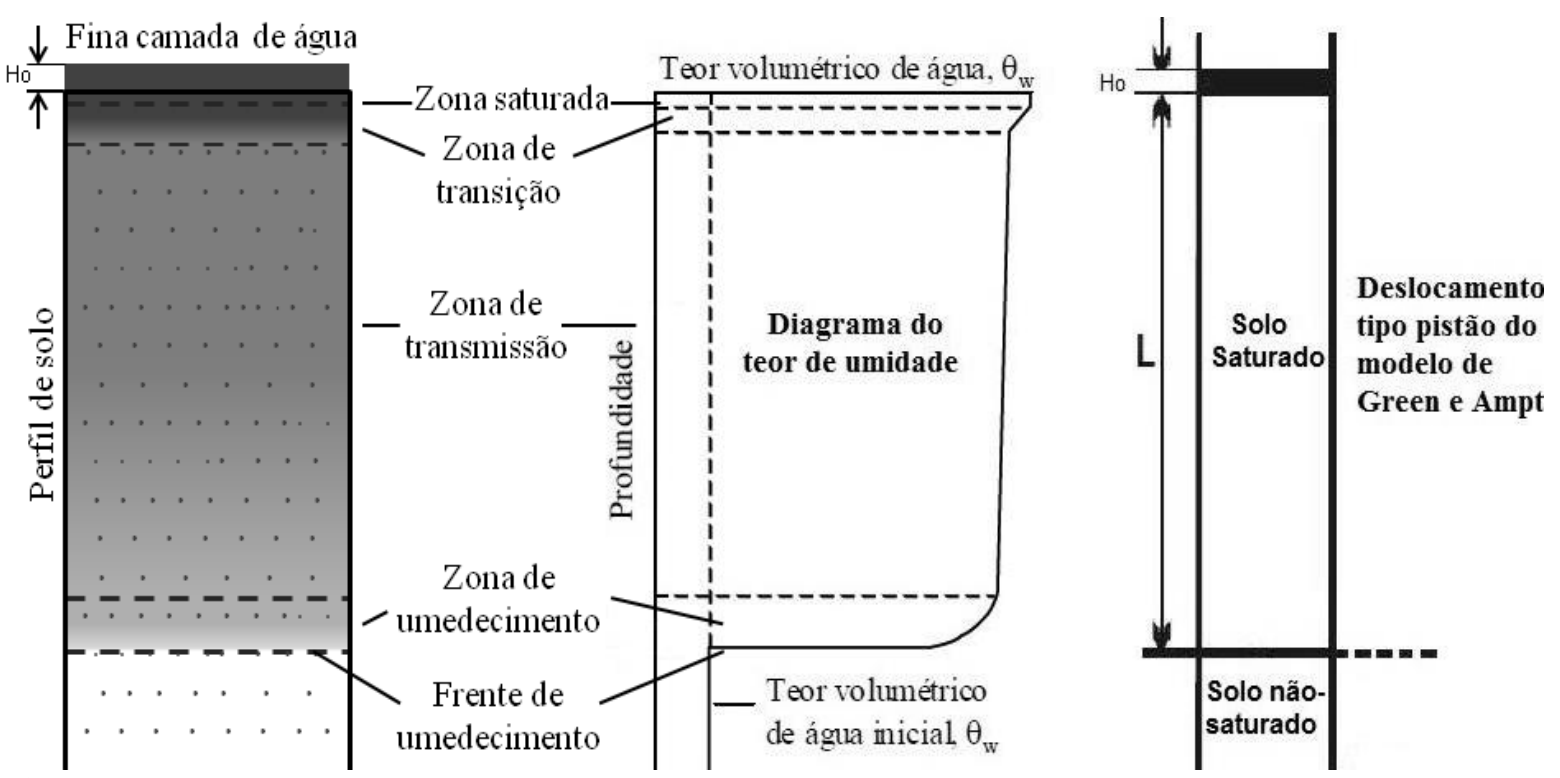

Figura 6 - Perfil de umedecimento do solo durante a infiltração (modificado de Oliveira,2003)

Figure 6- Wetting of the soil profile during infiltration (modified from Oliveira, 2003)

Uma pequena faixa de solo logo abaixo da superfície do terreno, permanece totalmente saturada (zona saturada) durante a precipitação. A zona de transição é caracterizada por uma diminuição rápida do conteúdo de água com a profundidade, se estendendo a alguns centímetros, dependendo da textura do solo. A terceira região corresponde à zona de transmissão é caracterizada pela variação de umidade quase inexistente e o movimento da água é governado pelos potenciais gravitacional e matricial. Esta zona, ao contrário das outras, tem sua espessura aumentando continuamente enquanto a carga hidráulica na superfície é mantida. Na zona de umedecimento o teor de água diminui acentuadamente com a profundidade a partir do teor de água da zona de transmissão para próximo do teor de água inicial do solo. Normalmente esta zona é muito fina e se encontra nas camadas mais profundas, representando o limite de alcance da água que infiltra no solo. Por fim, forma-se a frente de umedecimento, limite visível da movimentação da água no solo e consequentemente divisor entre as partes úmida e seca do perfil, onde ocorre maior gradiente de potencial de água (EPA, 1998).

Para a análise numérica dos resultados utilizou-se a modelagem proposta por Green e Ampt (1911), uma vez que seus parâmetros tem significado físico e podem ser obtidos diretamente em ensaios de campo, através da determinação da Condutividade hidráulica saturada e da sucção mátrica.

O modelo é baseado na Lei de Darcy e considera que a infiltração é governada por dois gradientes, o matricial e o gravitacional.

A expressão desenvolvida por Green e Ampt (1911) para a taxa de infiltração $\left(i, \mathrm{~mm} . \mathrm{h}^{-}\right.$ $\left.{ }^{1}\right)$ sob a condição de ponto de encharcamento (intensidade de precipitação igual à capacidade de infiltração) é dada pela equação 3 :

$i=K_{\text {sat }}\left(1+\frac{\Psi_{f}}{L}\right)$

(equação 3)

As variáveis da equação são a condutividade hidráulica saturada $\left(K_{\text {sat }}, \mathrm{mm} \cdot \mathrm{h}^{-1}\right)$ e os valores de carga de sucção $\left(\Psi_{f}\right.$, mm.c.a) na frente de umedecimento, além ainda da profundidade da frente de umedecimento $(L, \mathrm{~mm})$.

A equação 3 pode ser reescrita inserindo o volume total infiltrado (I) num instante t, quando a fronteira de umedecimento possui um comprimento igual a L (equação 4):

$i=K_{\text {sat }}\left(1+\Psi_{f} \frac{\left(\theta_{f}-\theta_{i}\right)}{I}\right)$

(equação 4)

Onde $\theta_{f}-\theta_{i}(-)$ é a variação de umidade volumétrica e a infiltração acumulada $(I, \mathrm{~mm})$.

Essas equações foram utilizadas nas analises dos resultados experimentais, uma vez que foram monitorados a profundidade da frente de umedecimento (L, mm) a infiltração acumulada (I, mm.h $\left.{ }^{-1}\right)$.

A qualidade do ajuste dos modelos foi avaliada através de regressões não lineares entre valores estimados e valores médios observados em cada tratamento estudado, juntamente 
com os coeficientes de determinação $\left(\mathrm{R}^{2}\right) . \mathrm{Na}$ avaliação foram também utilizados os seguintes índices estatísticos: coeficiente de massa residual (CMR), coeficiente de ajuste (CA) e eficiência (EF), conforme Zacharias et al. (1996) e Sentelhas et al. (1997). Esse indicadores foram obtidos à partir da equação 5 , da equação 6 e da equação 7 , onde $O_{i}$ são os valores observados, $P_{i}$ os valores estimados, $n$ o número de observações e $\bar{O}$ a média aritmética das observações:

$$
\begin{aligned}
& C M R=\left[\sum_{i=1}^{3} o_{i}-\sum_{i=1}^{n} P_{i}\right] / \sum_{i=1}^{n} o_{i} \\
& C A=\sum_{i=1}^{n}\left(O_{i}-\bar{O}\right)^{2} / \sum_{i=1}^{n}\left(P_{i}-\bar{O}\right)^{2}
\end{aligned}
$$

$E F=\left[\sum_{i=1}^{n}\left(O_{i}-\bar{O}\right)^{2}-\sum_{i=1}^{n}\left(O_{i}-P_{i}\right)^{2}\right] / \sum_{i=1}^{n n}\left(O_{i}-\bar{O}\right)^{2}$

(equação 7)

\section{RESULTADOS E DISCUSSÕES}

\section{Caracterização do solo}

As curvas granulométricas realizadas nas amostras após o primeiro e o último destorroamento são apresentadas na Figura 7.

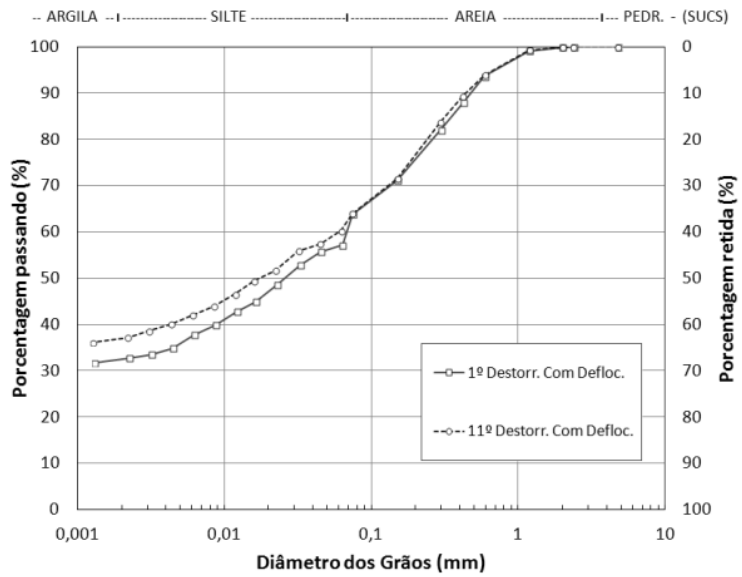

Figura 7 - Curvas granulométricas para o $1^{\circ}$ e $11^{\circ}$ destorroamento

Figure 7 - Granulometric Curves for the 1st and 11 th tremmenig

Pode-se verificar que o processo de reuso do solo nos ensaios provocou um aumento da porcentagem de finos de apenas 5,5\% devido à "quebra" de grãos no destorroamento. Porém, essa faixa de variação é inferior aos $15 \%$ da variação de finos observado no campo.
Esse efeito teve pouca influência nos valores dos limites de liquidez $(43 \%<\mathrm{LL}<45 \%)$ e de plasticidade $(28 \%<\mathrm{LP}<30 \%)$. Pelo Sistema Unificado de Classificação de Solo o material é classificado como um silte arenoso de baixa plasticidade - ML.

As características iniciais dos vinte e sete corpos-de-prova moldados para a determinação das curvas de retenção de umidade do solo (CRUS), são apresentadas na Tabela 2.

Tabela 2 - Propriedades físicas iniciais dos corpos de prova

Table 2 - Initial physical properties of the samples

\begin{tabular}{ccc}
\hline Propriedades & Média & $\begin{array}{c}\text { Desvio } \\
\text { padrão }\end{array}$ \\
\hline $\begin{array}{c}\text { Peso específico seco } \\
\left(\mathbf{K N}^{*} \mathbf{m}^{-3}\right)\end{array}$ & 1,19 & 0,01 \\
Índice de vazios & 1,30 & 0,02 \\
$\begin{array}{c}\text { Porosidade }(\%) \\
\text { Índice de compaci- } \\
\text { dade }\end{array}$ & $0,66,72$ & 0,51 \\
\hline
\end{tabular}

As curvas de retenção de umidade do solo (CRUS), ajustadas pela metodologia de Duplo Van Genutchen utilizada por Carducci et al. (2011), apresentaram comportamento bimodal (Figura 8), comum aos solos da região de clima tropical, que apresentam solos com duas classes de poros, classificados em poros estruturais (macroporos) e texturais (microporos), e que lhe conferem propriedades e comportamentos diferenciados (DE CARVALHO et al., 2012).

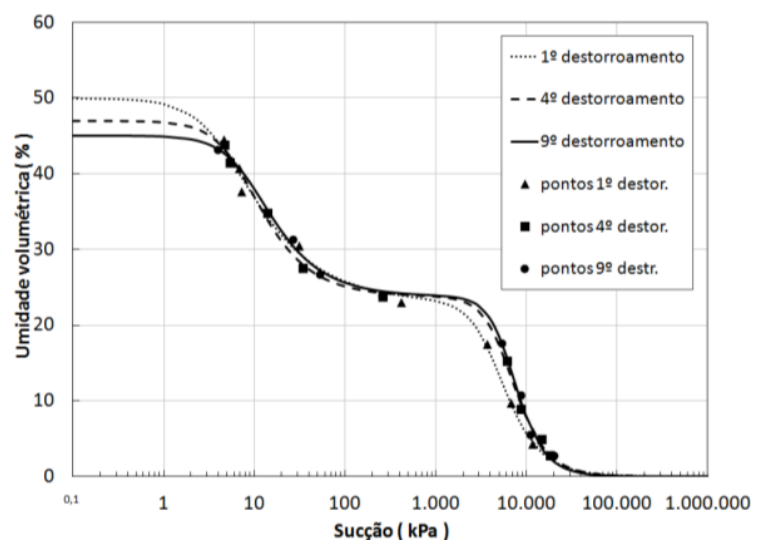

Figura 8 - Curvas Características para o $1^{\circ}, 4^{\circ}$ e $9^{\circ}$ destorroamento

Figure 8 - Characteristic Curves for the 1st, 4th and 9th tremmenig 
Observa-se também, na zona de efeito limite dos macroporos, uma diminuição do teor de umidade saturado com o reaproveitamento da amostra. Já nos microporos, na zona de transição, temos uma maior proximidade entre as curvas para os dois últimos destorroamentos. Essas observações reforçam o efeito de que ocorreu quebra dos grãos devido ao processo de destorroamento do solo.

As derivadas das curvas de retenção pa- ra determinação das distribuições dos poros são apresentadas na Figura 9.

O comportamento bimodal das curvas gerou dois picos de concentração de poros, um estrutural e outro textural, correspondentes à macro e a microporosidade, respectivamente. $\mathrm{O}$ efeito do reaproveitamento do solo é observado na redução da amplitude das curvas de distribuição e também no diâmetro médio dos poros.

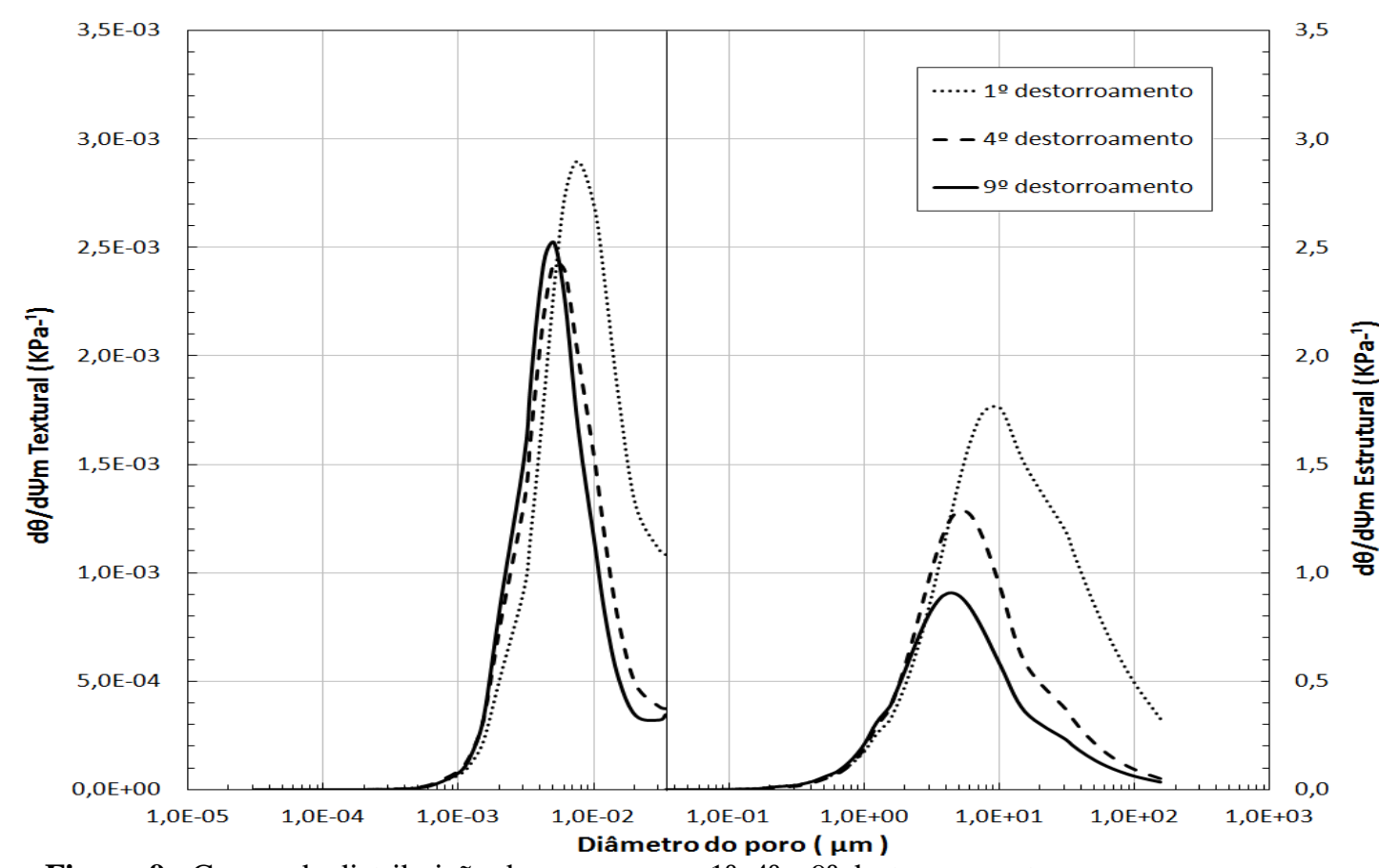

Figura 9 - Curvas de distribuição de poros para o $1^{\circ}, 4^{\circ}$ e $9^{\circ}$ destorroamento

Figure 9 - Distribution of poros curves for the 1st, 4 th and 9th tremmenig

\section{Simulações no Lisímetro}

Um total de 8 ensaios foi realizado para 4 diferentes declividades da superfície do solo $(5,15,30$ e $50 \%)$.

De acordo com o modelo teórico de Green-Ampt, de encharcamento permanente da superfície, ao se atingir a capacidade final de infiltração, na condição de fluxo subsuperficial constante, à mesma iguala-se a Condutividade Hidráulica Saturada $\left(\mathrm{K}_{\text {sat }}\right)$ do solo (ESPÍRITO SANTOS, 2011). As propriedades hidráulicas do solo, determinadas em cada ensaio, são apresentadas na Tabela 3.

Para a condição de regime permanente de fluxo, isto é, quando existia o paralelismo entre a curva de escoamento superficial mais escoamento subsuperficial e a curva de precipitação em função do tempo, os índices físicos das amostras ensaiadas foram re-calculadas considerando que o volume de vazio $(\mathrm{Vv})$ é igual ao volume de água retida $\left(\mathrm{V} \omega_{\text {ret }}\right)$, conforme apresentados na Tabela 4. 
Tabela 3 - Propriedades hidráulicas do solo para cada ensaio de infiltração

Table 3 - Soil hydraulic properties for each infiltration test

\begin{tabular}{ccccc}
\hline $\begin{array}{c}\text { Declividade } \\
\text { do Ensaio } \\
(\mathbf{\%})\end{array}$ & $\begin{array}{c}\text { Sequência do Destorro- } \\
\text { amento }\end{array}$ & $\begin{array}{c}\text { Velocidade/Taxa de } \\
\text { Infiltração } \\
(\mathbf{c m} / \mathbf{s})\end{array}$ & $\begin{array}{c}\text { Velocidade Per- } \\
\text { colação } \\
(\mathbf{c m} / \mathbf{s})\end{array}$ & $\begin{array}{c}\text { Retenção } \\
\left(\mathbf{c m}^{\mathbf{3}}\right)\end{array}$ \\
\hline $\mathbf{5}$ & $5^{\text {o }}$ & $3,21 \mathrm{E}-4$ & $3,24 \mathrm{E}-4$ & 14.212 \\
$\mathbf{5}$ & $9^{\text {o }}$ & $2,68 \mathrm{E}-4$ & $2,67 \mathrm{E}-4$ & 17.228 \\
$\mathbf{1 5}$ & $4^{\text {o }}$ & $3,30 \mathrm{E}-4$ & $3,30 \mathrm{E}-4$ & 14.169 \\
$\mathbf{1 5}$ & $7^{\text {o }}$ & $2,51 \mathrm{E}-4$ & $2,56 \mathrm{E}-4$ & 13.622 \\
$\mathbf{3 0}$ & $2^{\text {o }}$ & $3,07 \mathrm{E}-4$ & $3,14 \mathrm{E}-4$ & 14.614 \\
$\mathbf{3 0}$ & $6^{\text {o }}$ & $2,56 \mathrm{E}-4$ & $2,56 \mathrm{E}-4$ & 13.221 \\
$\mathbf{5 0}$ & $8^{\text {o }}$ & $2,20 \mathrm{E}-4$ & $2,19 \mathrm{E}-4$ & 17.763 \\
$\mathbf{5 0}$ & $10^{\circ}$ & $2,47 \mathrm{E}-4$ & $2,47 \mathrm{E}-4$ & 17.790 \\
\hline
\end{tabular}

Tabela 4 - Propriedades físicas do solo para cada ensaio de infiltração

Table 4 - Physical properties of the soil for each test infiltration

\begin{tabular}{|c|c|c|c|c|c|c|}
\hline $\begin{array}{c}\text { Ensaio } \\
\text { Declividade } \\
(\%)\end{array}$ & $\begin{array}{c}\text { Umidade } \\
\text { Higroscópica } \\
(\%)\end{array}$ & $\begin{array}{c}\gamma_{\text {nat }} \\
\left(\mathrm{g} / \mathbf{c m}^{3}\right)\end{array}$ & $\begin{array}{c}\gamma_{d l} \\
\left(\mathrm{~g} / \mathrm{cm}^{3}\right)\end{array}$ & $\mathrm{e}$ & $\begin{array}{c}\eta \\
(\%)\end{array}$ & $\begin{array}{c}S \\
(\%)\end{array}$ \\
\hline 5 & 1,74 & 1,56 & 1,54 & 0,78 & 43,86 & 6,11 \\
\hline 5 & 1,37 & 1,30 & 1,28 & 1,14 & 53,17 & 1,29 \\
\hline 15 & 4,80 & 1,61 & 1,54 & 0,78 & 43,73 & 16,90 \\
\hline 15 & 1,66 & 1,61 & 1,59 & 0,73 & 42,04 & 6,26 \\
\hline 30 & 2,22 & 1,54 & 1,50 & 0,82 & 45,10 & 7,41 \\
\hline 30 & 1,58 & 1,65 & 1,62 & 0,69 & 40,81 & 2,47 \\
\hline 50 & 1,63 & 1,26 & 1,24 & 1,21 & 54,82 & 3,69 \\
\hline 50 & 1,26 & 1,25 & 1,25 & 1,22 & 54,91 & 2,84 \\
\hline
\end{tabular}

Onde: $\gamma_{\text {nat: }}$ peso específico natural; $\gamma_{\mathrm{d}}$ : peso específico seco; e: índice de vazios; $\eta$ : porosidade; S: Grau de saturação.

A variabilidade dos resultados é decorrente das dificuldades inerentes ao procedimento de preparo do solo, lançamento e compactação. No entanto, as propriedades físicas são representativas quando comparadas com as determinadas no campo. Sendo assim, as análises a seguir serão realizadas segundo faixas de valores.
A influência da declividade da superfície no processo de infiltração é apresentada na Figura 10, Figura 11 e Figura 12. A Figura 10 ilustra as evoluções das frentes de umedecimento. A Figura 11 ilustra os escoamentos superficiais. A Figura 12 ilustra os fluxos de base para duas classes de índice de vazios "e": 0,69 a 0,82 e 1,14 a 1,22 . 

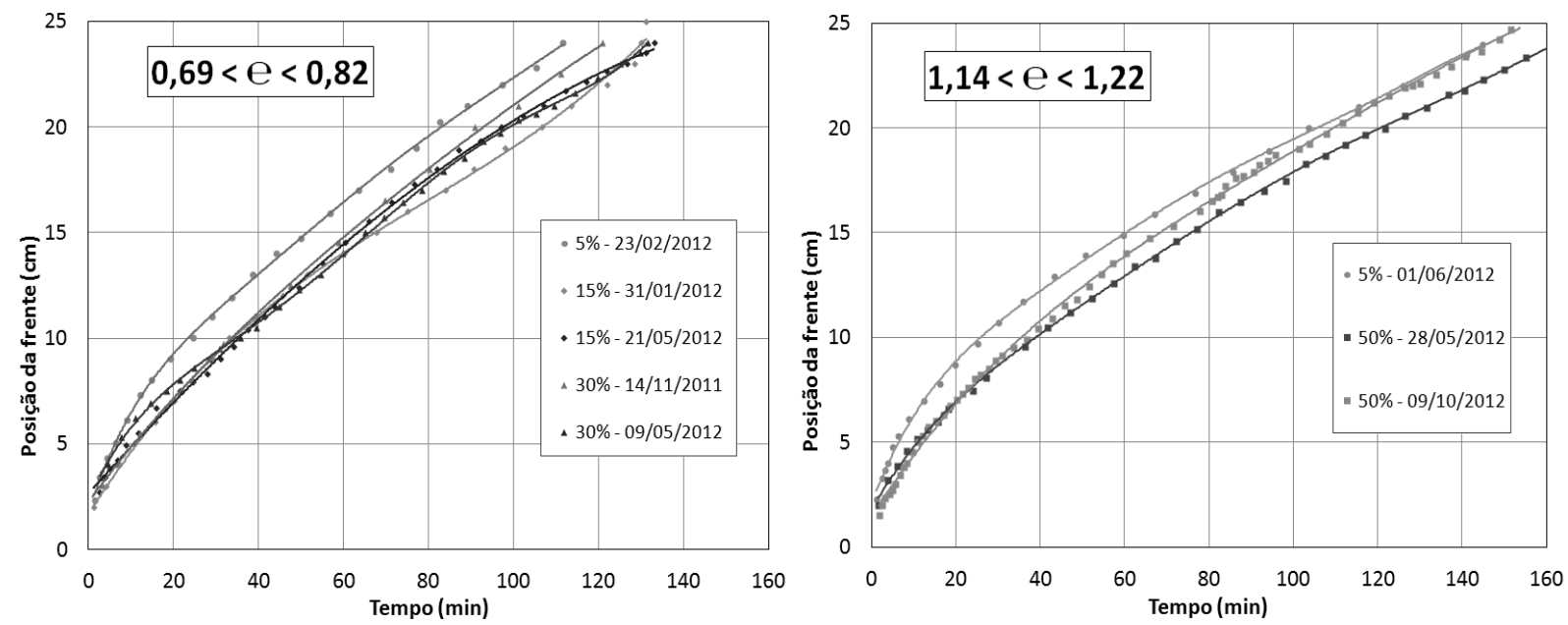

Figura 10 - Frentes de umedecimento separadas em duas classes de índices de vazios (e)

Figure 10 - Wetting fronts in two separate classes of void ratio (e)
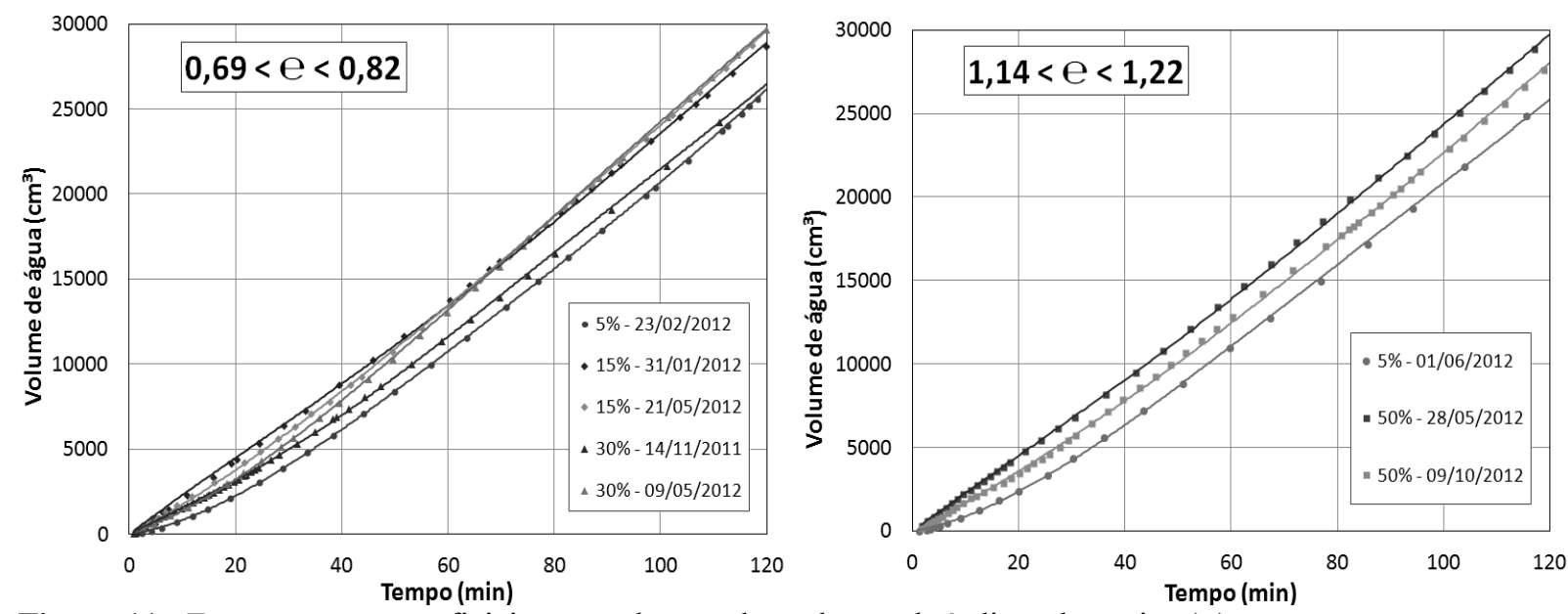

Figura 11 - Escoamentos superficiais separados em duas classes de índices de vazios (e)

Figure 11 - Runoff separated into two classes of void ratio (e)
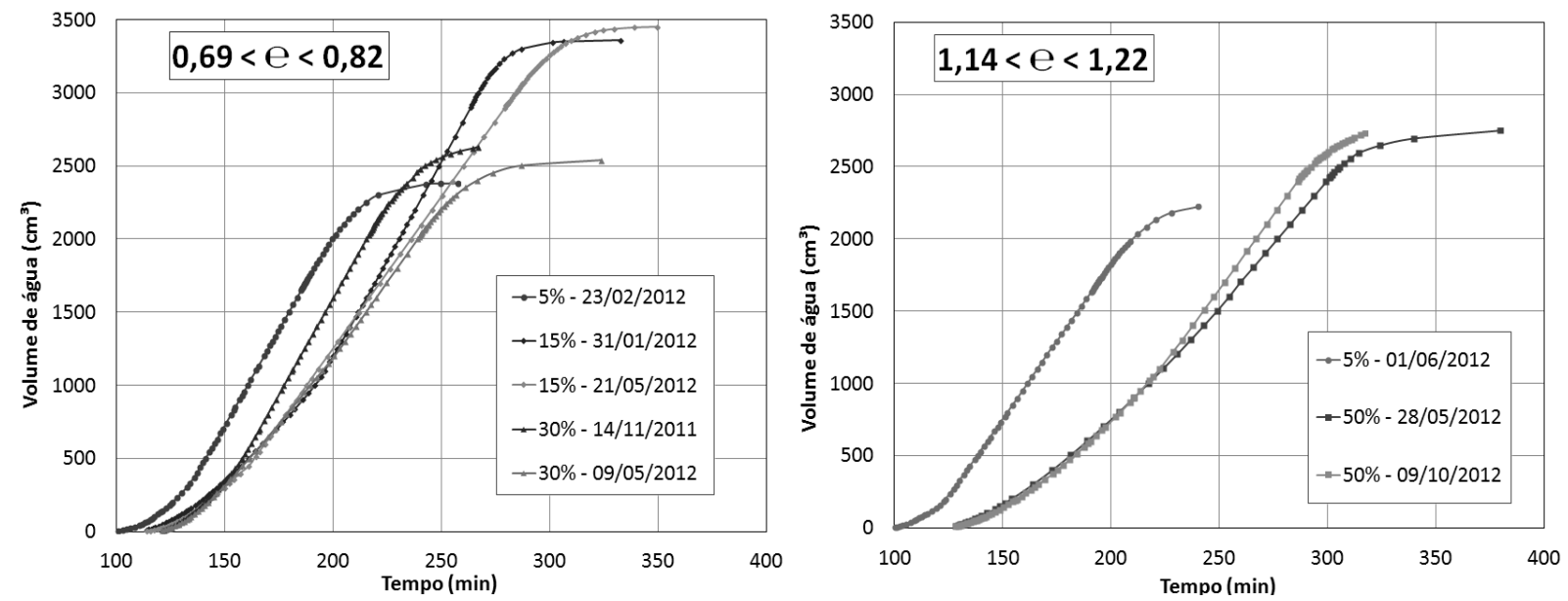

Figura 12 - Escoamentos subsuperficiais separados em duas classes de índice de vazios (e)

Figure 12 - Subsuperficial flows separated into two classes of voids (e) 
Da Figura 10 destaca-se, para índices de vazios menores, uma maior taxa de infiltração para 5\% de declividade. As declividades de $15 \%$ e $30 \%$ apresentaram oscilações, ficando assim todas dentro de uma mesma faixa de variação.

Para índices de vazios maiores, uma maior taxa de infiltração para 5\% de declividade também é observada, porém com menor amplitude.

Com relação aos escoamentos superficial Figura 11) e subsuperficiais (Figura 12) os mesmos comportamentos são observados, com destaque aos gráficos dos escoamentos subsuperficiais que evidenciam a influência dos índices de vazios e a clara influência da declividade no escoamento subsuperficial entre as declividades de $5 \%$ e $50 \%$.

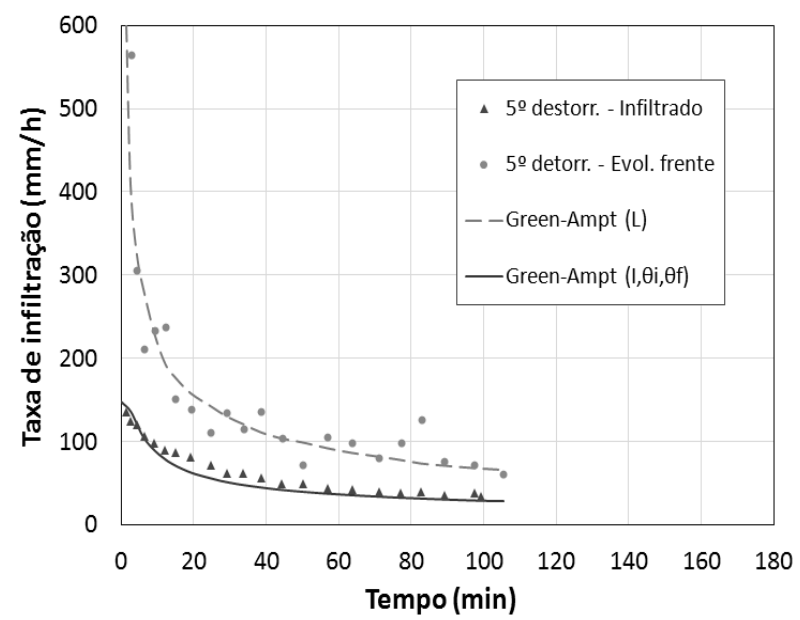

Figura 13 - Modelagem do ensaio de declividade 5\% Figure 13- Modeling the test slope 5\%

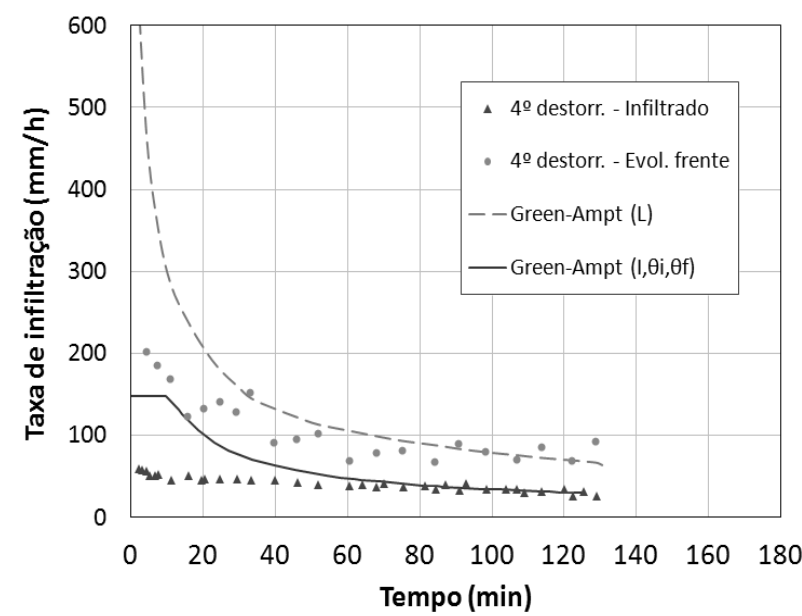

Figura 14 - Modelagem do ensaio de declividade $15 \%$ Figure 14- Modeling the test slope $15 \%$

\section{Modelagem Teórica}

As simulações numéricas foram analisadas com base nos dados das evoluções das frentes de umedecimento e das taxas de infiltração obtidos dos ensaios com superfície permanentemente encharcada de (equação 3 e equação 4).

As Figura 13 a Figura 16 apresentam os resultados da aplicação do modelo para cada ensaio realizado. As curvas apresentadas descrevem, respectivamente, a frente de umedecimento e a zona de transmissão ao longo do perfil de solo, nos quais as diferenças existentes estão relacionadas ao teor de umidade e correspondente sucção matricial. As sucções na frente de umedecimento $\left(\Psi_{\mathrm{f}}\right)$, correspondentes à umidade residual e umidade da primeira entrada de ar $\left(\mathrm{U}_{\text {sat }}\right)$, foram obtidas das CRUS.
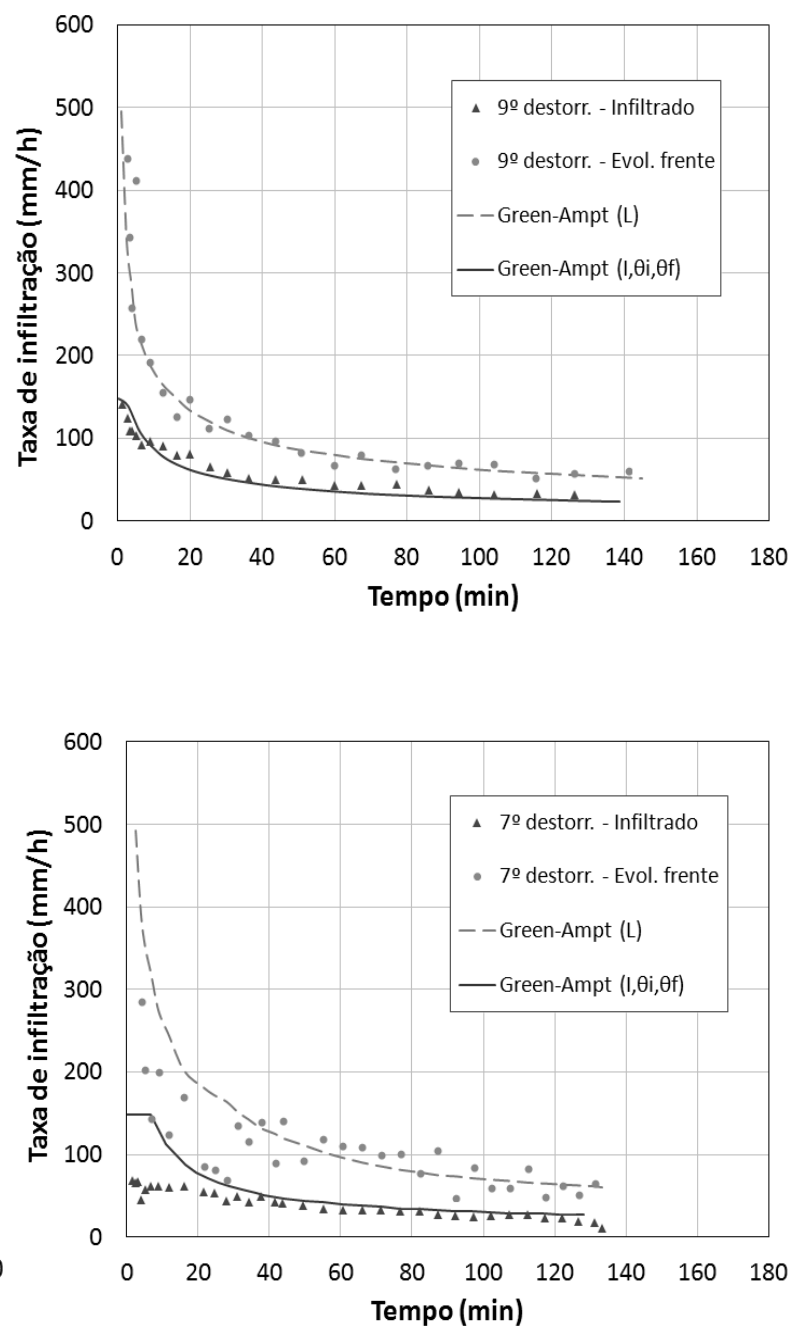


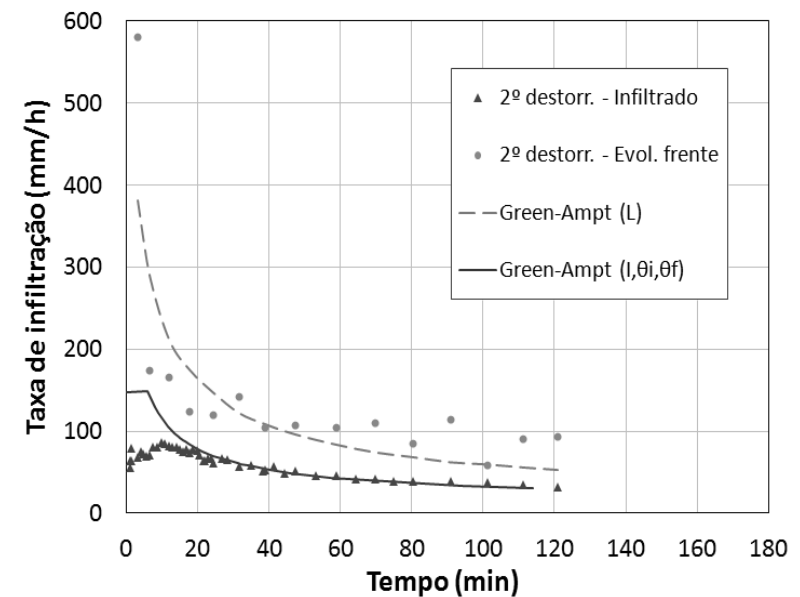

Figura 15 - Modelagem do ensaio de declividade 30\% Figure 15 - Modeling the test slope 30\%

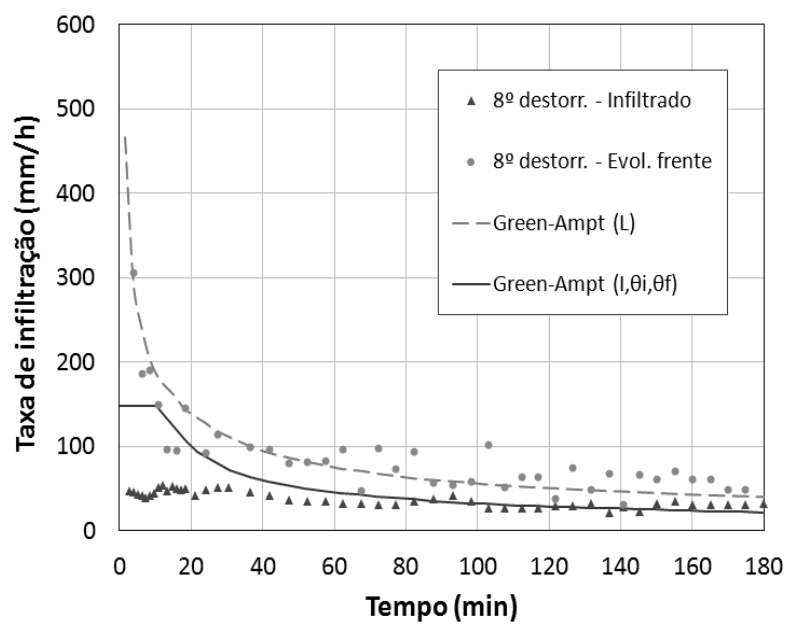

Figura 16 - Modelagem do ensaio de declividade 50\% Figure 16 - Modeling the test slope 50\%

Os índices estatísticos calculados são apresentados na Tabela 5.

A condição ideal seria a concordância entre os pares de valores obtidos experimentalmente e ajustados, isto é, $\mathrm{CA}=\mathrm{EF}=1$ e $\mathrm{CMR}$ $=0$ (BRITO et al., 2009).

Os resultados demonstram, no entanto que o modelo representou de forma satisfatória os dados experimentais de evolução da frente de umedecimento. Quanto à taxa de infiltração (zona de transmissão), apenas a declividade de $5 \%$ apresentou boa concordância ao longo de todo o ensaio. Para os demais ensaios a modelagem apresenta maior taxa de infiltração que os valores experimentais nos trechos iniciais, conforme indicam também os índices estatísticos da segunda parte da Tabela 5, que se aproximaram mais da unidade para $\mathrm{R}^{2}, \mathrm{CA}$ e $\mathrm{EF}$, e de 0 (zero) para CMR na declividade de $5 \%$.

As Figura 17 e Figura 18 representam o
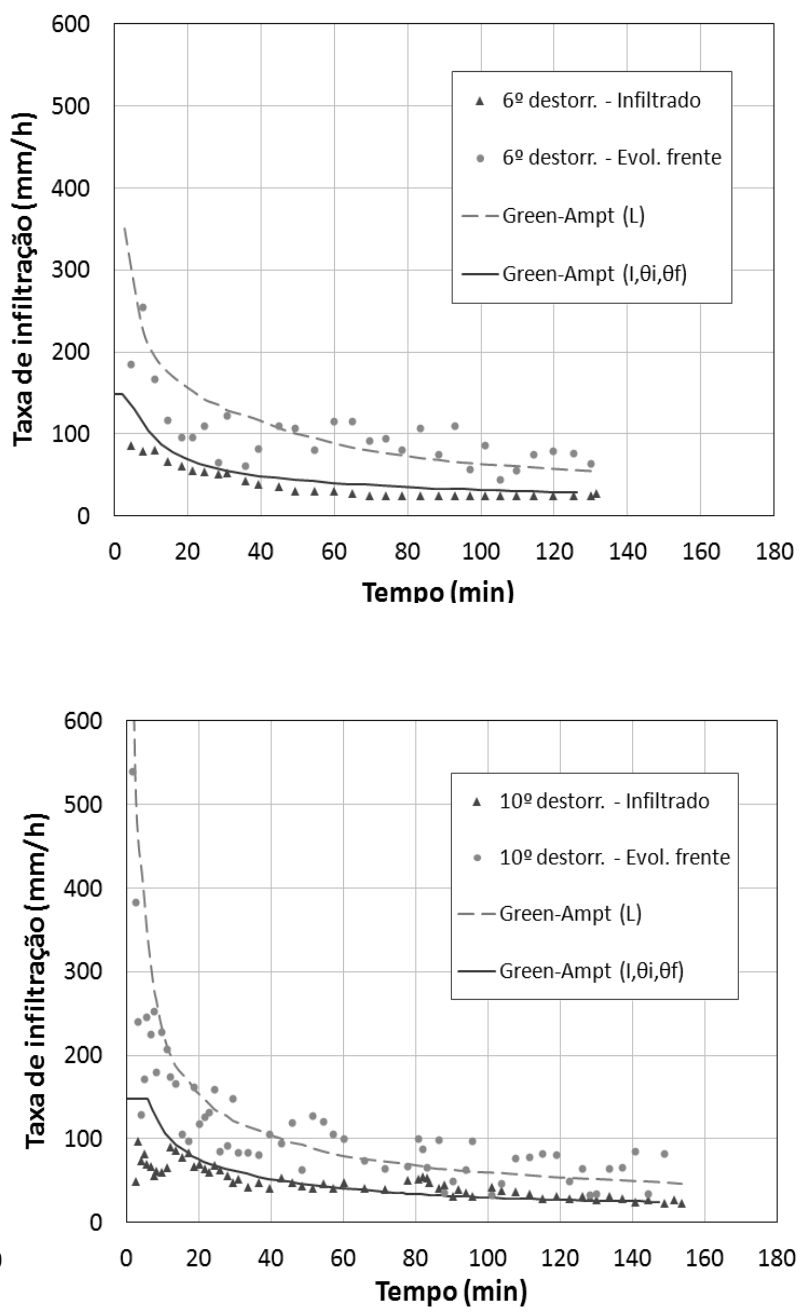

processo de avanço do perfil de umidade para intervalos de tempo preestabelecidos $(2,4,6$, $8,10,20,30,40,50,60,70,80,90$ e 100 minutos).

Cada perfil de umidade foi construído com base na relação entre as profundidades da frente de umedecimento e da zona de transmissão (Figura 13 a Figura 16) relacionando-as com o avanço da frente de umedecimento medido. A forma curva da frente de umedecimento ilustra a variação da umidade existente entre as modelagens obtidas pelas equações 3 e 4 ao qual representa a espessura da zona de umedecimento. Pelas Figura 17 e Figura 18 observa-se um maior avanço da frente de umedecimento dos perfis de umidade para $5 \%$ declividade em relação aos demais perfis. Entre os perfis de $15 \%$ e $30 \%$ de declividade, essa redução é pequena. 
Tabela 5 - Índices estatísticos

Table 5 - Statistical indices

\begin{tabular}{ccccc}
\hline $\begin{array}{c}\text { Declividade } \\
\text { do ensaio } \\
(\boldsymbol{\%})\end{array}$ & \multicolumn{1}{c}{ Índices estatísticos calculados } & (frente de umedecimento) \\
\cline { 2 - 5 } $\mathbf{2}$ & $\mathbf{R}^{\mathbf{2}}$ & $\mathbf{C M R}$ & $\mathbf{C A}$ & $\mathbf{E F}$ \\
$\mathbf{5}$ & 0,8668 & 0,0456 & 1,4818 & 0,8502 \\
$\mathbf{5}$ & 0,8933 & 0,0741 & 1,7258 & 0,8458 \\
$\mathbf{1 5}$ & 0,7363 & $-0,1880$ & 1,4931 & 0,7110 \\
$\mathbf{1 5}$ & 0,6874 & $-0,1837$ & 0,9549 & 0,5785 \\
$\mathbf{3 0}$ & 0,7098 & 0,0880 & 1,6471 & 0,6936 \\
$\mathbf{3 0}$ & 0,5933 & 0,0412 & 3,0957 & 0,5353 \\
$\mathbf{5 0}$ & 0,8425 & 0,0713 & 1,8750 & 0,8084 \\
$\mathbf{5 0}$ & 0,7291 & $-0,1552$ & 0,4336 & 0,2600 \\
\hline & Índices estatísticos calculados (zona de transmissão) \\
\hline $\mathbf{5}$ & 0,9127 & 0,1853 & 0,7614 & 0,6444 \\
$\mathbf{5}$ & 0,9325 & 0,0084 & 0,5762 & 0,8086 \\
$\mathbf{1 5}$ & 0,7243 & $-0,3905$ & 0,0354 & $-20,0950$ \\
$\mathbf{1 5}$ & 0,8229 & 0,2681 & 0,2100 & $-1,0544$ \\
$\mathbf{3 0}$ & 0,7731 & $-0,3096$ & 0,1060 & $-4,5433$ \\
$\mathbf{3 0}$ & 0,9231 & $-0,3470$ & 0,3384 & 0,0506 \\
$\mathbf{5 0}$ & 0,5783 & $-0,2435$ & 0,0791 & $-7,4505$ \\
$\mathbf{5 0}$ & 0,6798 & $-0,1358$ & 0,2467 & $-0,7986$ \\
\hline
\end{tabular}

Com relação às zonas de umedecimento, os gráficos indicam que a diferença entre a evolução da zona de transmissão e a frente de umedecimento diminui com o aumento da declividade. Essas diferenças, entre as profundidades atingidas pelas duas zonas, foram de 0,20 cm para os ensaios de $5 \%$ e $30 \%(0,69<$ e $<$ 0,82 ). Os ensaios de $5 \%$ e $50 \%$ de declividade apresentaram uma diferença de $1,27 \mathrm{~cm}(1,14<$ $\mathrm{e}<1,22$ ).

As diferenças de comportamento são da ordem de $6,7 \%$ para os ensaios de $5 \%$ e $30 \%$ de declividade considerando o índice de vazios entre 0,69 e 0,82 . Com relação à faixa de índices de vazios entre 1,14 e 1,22 , as diferenças médias ficaram em torno de $43,2 \%$ para os ensaios com $5 \%$ e $50 \%$ de declividade.

Para a faixa de índices de vazios menores, os avanços das frentes de umedecimento são maiores. Para a faixa de índice de vazios maiores, ao longo dos ensaios, observa-se uma redução da distância entre a frente de umedecimento e a zona de transmissão com o aumento da declividade. Isso demonstra a influência da macroporosidade do solo no processo de infiltração. 

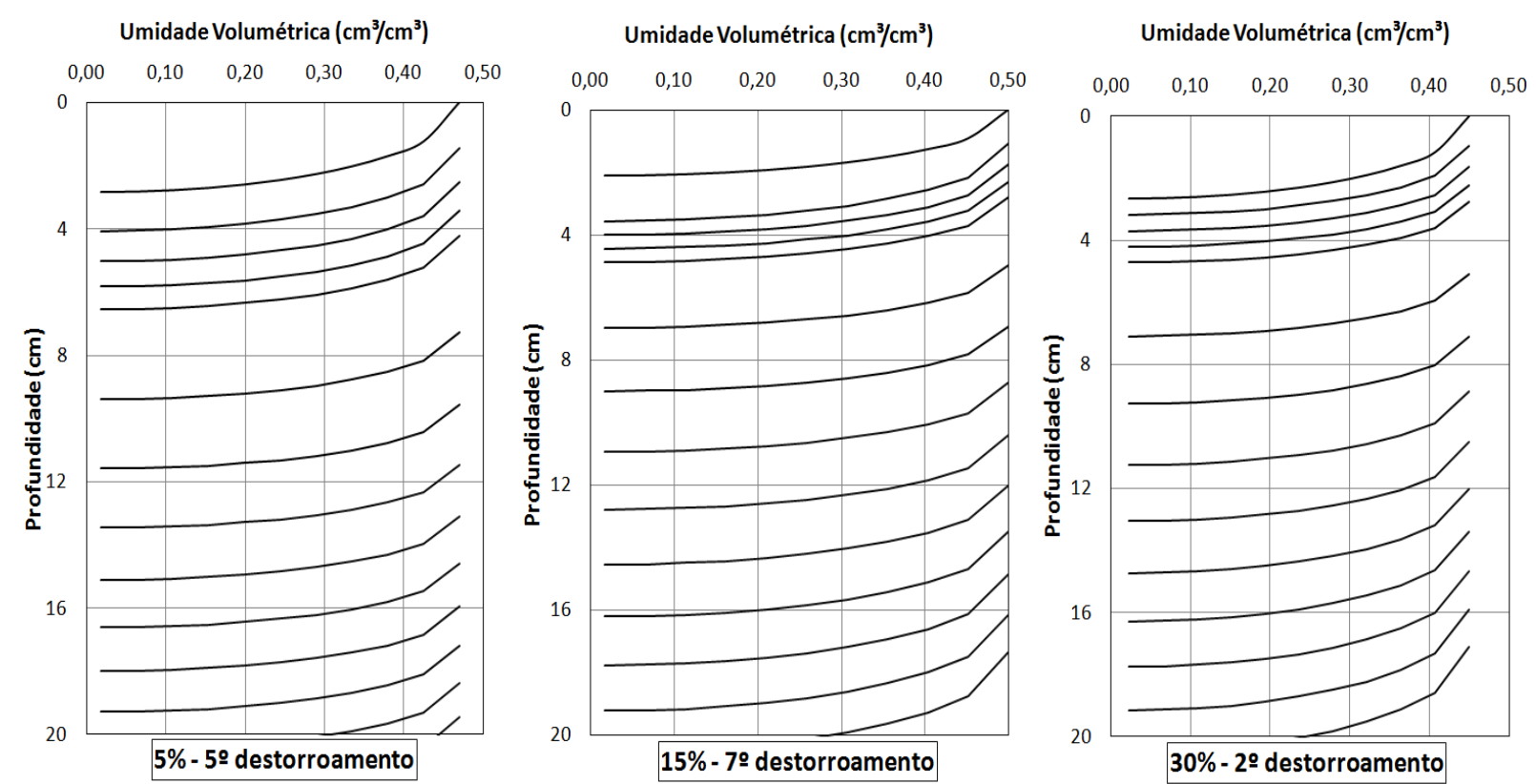

Figura 17 - Perfis de umidade para a classe de e variando de 0,69 à 0,82

Figure 17 - Moisture profiles for the class e ranging from 0.69 to 0.82
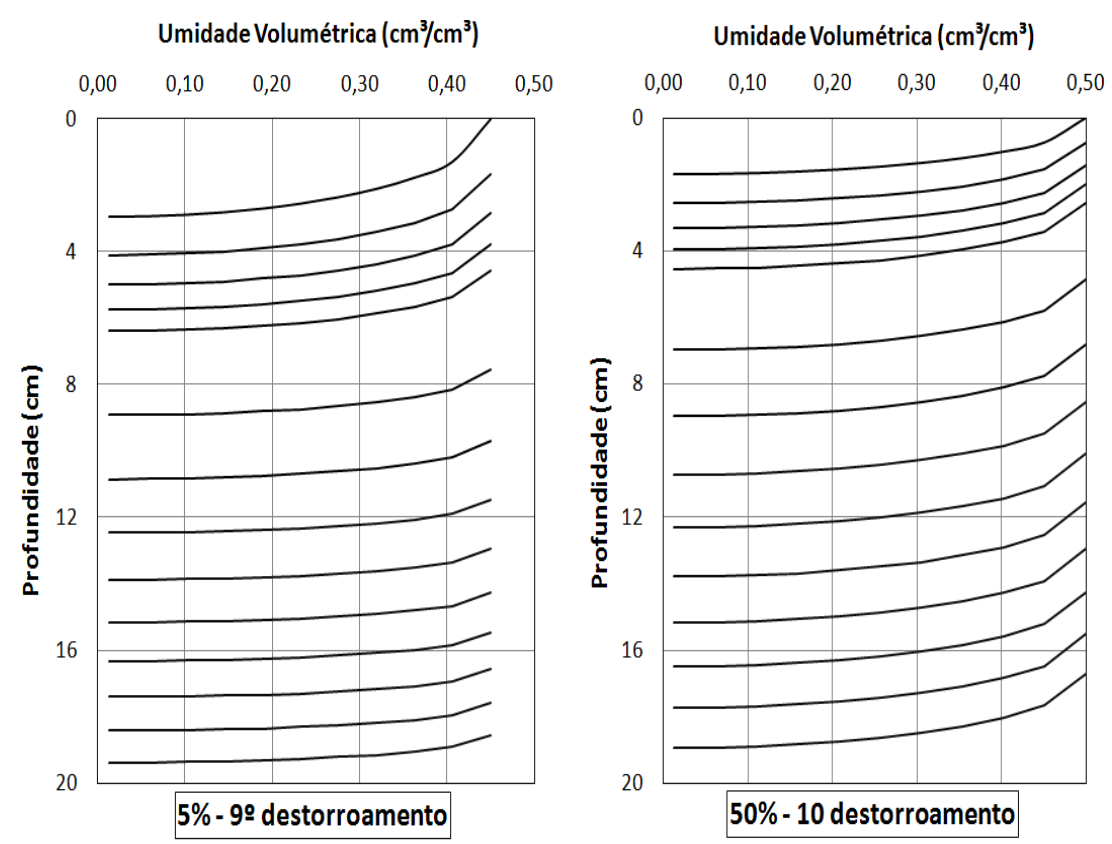

Figura 18 - Perfis de umidade para a classe de e variando de 1,14 à 1,22

Figure 18 - Moisture profiles for the class e ranging from 1.14 to 1.22

\section{CONCLUSÕES}

$\mathrm{O}$ equipamento mostrou-se adequado para a compreensão do mecanismo de transferência da água superficial para o interior do solo e consequente avanço da frente de umedecimento com a profundidade.

O procedimento de reutilização da amostra de solo provocou a quebra de grãos gerando um aumento do teor de finos. Essa variação ficou abaixo da faixa natural de variação observada no campo.

Os resultados dos ensaios de infiltração demonstram uma maior evolução da frente de infiltração para a superfície com 5\% de declividade em relação as demais. As declividades, 15 e $30 \%$, apresentam oscilações nas curvas, ficando assim todas dentro de uma mesma faixa de varia- 
ção.

Com relação ao escoamento superficial e subterrâneo, os mesmos comportamentos são observados, com destaque aos resultados dos escoamentos subterrâneos que evidenciam as diferenças dos índices de vazios em seus trechos lineares e a clara influência da declividade no escoamento básico entre as declividades de $5 \%$ e $50 \%$.

$\mathrm{O}$ aumento da declividade gerou uma redução da velocidade do avanço da frente de ume-

\section{REFERÊNCIAS}

ABNT. Massa específica real dos grãos: NBR 6508. associação Brasileira de Normas Técnicas. Rio de Janeiro. 1984.

ABNT. Solo - Análise Granulométrica: NBR - 7181. Associação Brasileira de Normas Técnicas. Rio de Janeiro. 1984.

ABNT. Solo - Determinação do limite de liqudez: NBR - 6459. Associação Brasileira de Normas Técnicas. Rio de Janeiro. 1984.

ABNT. Solo - Determinação do limite de plasticidade: NBR- 7180. Associação Brasileira de Normas Técnicas. Rio de Janeiro. 1984.

ABNT. Amostras de Solo - Preparação para ensaios de compactação e ensaios de caracterização: NBR 6457. Associação Brasileira de Normas Técnicas. Rio de Janeiro. 1986.

ABNT. Solo - Determinação do teor de umidade natural: NBR - 6457. Associação Brasileira de Normas Técnicas. Rio de Janeiro. 1986.

AHRENDT, A. Movimentos de massa gravitacionais - Proposta de um sistema de previsão: Aplicação na área urbana de Campos de Jordão - SP. Tese de Doutorado - Escola de Engenharia de São Carlos Universidade de São Paulo. São Carlos, p. 390. 2005.

ALLEN, R. G.; HOWELL, T. A.; PRUITT, W. O. Lisymeter for evapotranspiration and environmental measurements. Proc. International Symposium on Lisymetry, ASCE, New York, p. 444, 1991.

ALMEIDA, A. O.; PAES JUNIOR, N. S.; BERNARDES, G. P. Análise dos Processos de Infiltração, Percolação, Retenção e Evaporação em Solos Arenosos utilizando Lisímetros. XVI Congresso Brasileiro de Mecânica dos Solos e Engenharia Geotécnica, Porto de Galinhas - PE, Setembro 2012.

ASTM. Standard test method for measurement of soil potential (suction) using Filter Paper. American Society for Testing and Materials - D5298. [S.1.]. 1994. decimento em relação à zona de transmissão, com uma variação de cerca de $43,2 \%$ entre $5 \%$ e $50 \%$ de declividade.

Com relação à variação do índice de vazios, os resultados apontam um maior avanço da frente de umedecimento com a diminuição do índice, sendo no entanto, mais lento o avanço das zonas de transmissão, confirmando a influência da macroporosidade do solo no processo de infiltração.

BARCELOS, A. A.; CASSOL, E. A.; DENARDIN, J. E. Infiltração de água em um latossolo vermelho escuro sob condições de chuva intensa em diferentes sistemas de manejo. R. Bras. Ci. Solo, n. 23, p. 35-43, 1999 .

BERTONI, J.; LOMBARDI NETO, F. Conservação do Solo. São Paulo: Ícone, 1999.

BRITO, A. S. et al. Desempenho do tenciômetro com diferentes sistemas de leitura. Revista brasileira de Ciência do Solo, Viçosa, v. 33, n. 1, p. 17-24, 2009.

CAMARINHA, P. I. M. Mapeamento do potecial de infiltração como subsídio ao planejamento de microbacias de cabeceira. Uma proposta metodológica utilizando geotecnologias. Dissertação (Mestrado) Universidade Estadual Paulista (UNESP). Bauru, p. 120. 2011.

CARDUCCI, C. E. et al. Modelagem da curva de retenção de água de latossolos utilizando a equação Duplo Van Genuchten. Revista Brasileirade Ciências do Solo, n. 35, p. 77-86, 2011.

CECÍlLIO, R. A. Aplicação da equação de GreenAmpt na modelagem da infiltração de água em Latossolo Vermelho-Amerelo estratificado. Tese de Doutorado - Universidade Federal de Viçosa. Viçosa, MG, p. 118. 2002.

ESPÍRITO SANTO, A. F. D. Condutividade hidráulica saturada em função do tipo e uso do solo e método de determinação. Dissertação de Mestrado, Universidade de Brasília - Faculdade de Agronomia e Medicina Veterinária. Brasília, p. 34. 2011.

FELTRINI, R. M. Comportamento das variáveis hidrológicas do balanço hídrico à partir de dados lisimétricos. Dissertação de Mestrado, UFSM. [S.1.]. 2009 .

MARINHO, F. A. M. Medição de sucção com o método do papel filtro. X Congresso Brasileiro de Mecânica dos Solos e Engenharia de Fundações, Foz do Iguaçu, PR, v. 2, p. 515-522, 1994. 
MEDEIROS, A. T. Estimativa da evapotranspiração à partir da equação de Pehman-Monteith, de medidas lisimétricas e de equações empíricas. Tese de Doutorado, Escola Superior de Agricultura "Luiz de Queiros", ESALQ. [S.1.]. 2002.

MIYAZAKI, T. Water flow in soils. $2^{\mathrm{a}}$. ed. New York: Taylor \& Francis, 2006. 418 p.

MUALEM, Y. A new model for predicting the hydraulic condutivity of unsaturated porous media. Water Res. Res., v. 12, p. 513-522, 1976.

OLIVEIRA, D. R. Análise da interação soloatmosfera durante a secagem para a argila porosa de Brasília. Dissertação de Mestrado - Departamento de Engenharia Civil e Ambiental - Universidade de Brasília. Brasília, DF, p. 168. 2003. (Publicação G. DM 110/03).

PERUCHI, F. Evapotranspiração real à partir de medidas lisimétricas e sob diferentes condições de disponibilidade hídrica. Dissertação de mestrado, Escola de Engenharia de São Carlos, USP. [S.1.]. 2009.

PRUSKI, F. F. et al. Infiltração da água no solo. Engenharia na Agricultura. Caderno Didático 25, p. 26. 1997.

SANTOS, R. A. Propriedades de retenção de çagua por espaços porosos não homogêneos: Experimentos de laboratório e simulação computacional. Dissertação de Mestrado - Universidade Estadual de Ponta Grossa. Ponta Grossa, p. 121. 2005.
SENTELHAS, P. C. et al. Análise comparativa de dados meteorológicos obtidos por estações convencionais e automáticas. Revista Brasileira de Agrometeorologia, v. 5, p. 215-221, 1997.

SOARES, A. B. Fluxo de Água em Talude Arenoso:Modelagem Física e Numérica. Tese de Doutorado - COPPE / UFRJ. Rio de Janeiro, p. 233. 2006.

TAMI, D.; HARARDJO, H.; LEONE, E. Effects of Hysteresis on Steady-State Infiltration in Unsaturated Slopes. Journal of Geotechnical and Geoenvironmental Engineering, ASCE, v. 130, n. 9, p. 956-966, February 2004.

TUCCI, C. E. M. Hidrologia: ciência e aplicação. $2^{\mathrm{a}}$. ed. Porto Alegre: Ed. da Universidade: ABRH: EDUSP, 1993. 943 p.

VALLEJO, L. R. A influência do "Litter" na distribuição das águas pluviais. Dissertação de Mestrado Instituto de Geociencias - UFRJ. Rio de Janeiro, p. 88. 1982.

VIEIRA, A. M. Estudo de barreiras capilares como cobertura final de aterro de resíduos. Tese de Doutorado - Escola Politécnica da Universidade de São Paulo - USP. São Paulo. 2005.

ZACHARIAS, S.; HEATWOLE, C. D.; COAKLEY, C. W. Robuste quantitative techniques for validating pesticide transport models. Trans. Am. Soc. Agric. Eng., v. 39, p. 47-54, 1996. 